\title{
A venomous visitor from the tropics
}

\author{
Zain Chagla MSc MD ${ }^{1}$, Andrea K Boggild MSc MD2,3,4, Sumontra Chakrabarti MD ${ }^{4,5}$
}

\section{CASE PRESENTATION}

A 54-year-old man presented to the emergency room following a scorpion sting to the right index finger. He had been unloading a shipment of mangoes from South America and noted a small scorpion in the box, which he picked up and then killed after the sting (Figure 1A). Following the envenomation, he experienced acute paresthesia localized to the right arm, up to the elbow. He reported no fasciculations, spasms, myoclonus or any other focal or generalized neurological symptoms at that time. Review of systems was otherwise unremarkable. Medical history was only remarkable for a remote smoking history. He was on no regular medications and had no known drug allergies.

On initial examination, he was afebrile, with a blood pressure of $125 / 70 \mathrm{mmHg}$ sitting, heart rate of 70 beats/min, oxygen saturation of $98 \%$ on room air and a respiratory rate of 20 breaths $/ \mathrm{min}$. He was in no apparent distress. The distal interphalangeal joint of his right finger was swollen and erythematous, with an obvious puncture mark present. No sensory or motor abnormalities were noted, and reflexes were normal in the right upper extremity. No lymphadenopathy was noted. Cardiovascular, respiratory and abdominal examinations were all within normal limits.

Initial white blood cell count was $10.1 \times 10^{9} / \mathrm{L}$, hemoglobin $144 \mathrm{~g} / \mathrm{L}$ and platelets $317 \times 10^{9} / \mathrm{L}$. Sodium was $139 \mathrm{mmol} / \mathrm{L}$, potassium $3.9 \mathrm{mmol} / \mathrm{L}$, chloride $106 \mathrm{mmol} / \mathrm{L}$ and bicarbonate $24 \mathrm{mmol} / \mathrm{L}$. Creatinine was $66 \mu \mathrm{mol} / \mathrm{L}$, aspartate transaminase $22 \mathrm{U} / \mathrm{L}$, alanine transaminase $31 \mathrm{U} / \mathrm{L}$, alkaline phosphatase $110 \mathrm{U} / \mathrm{l}$, total bilirubin $3 \mu \mathrm{mol} / \mathrm{L}$, creatinine kinase $155 \mathrm{U} / \mathrm{L}$ and lipase $114 \mathrm{U} / \mathrm{L}$. In the emergency room, he was monitored for $5 \mathrm{~h}$ with no progression of upper extremity paresthesia. Local poison control was contacted, but believed that antitoxin was not needed. The patient was discharged home with symptomatic management, including nonsteroidal anti-inflammatory drugs. He was assessed as an outpatient $24 \mathrm{~h}$ later, and experienced regression of paresthesia to the wrist and had developed significant spasms in his right hand. He was prescribed benzodiazapines for symptomatic management, with resolution of his symptoms. He was assessed a few weeks following the envenomation and had some residual paresthesia localized to the bite site without any other sensory symptoms or muscular spasms.

\section{DISCUSSION}

Along with spiders, ticks and mites, scorpions are members of the Arachnida, all of which have eight legs (Figure 1B). Scorpion envenomation is a common cause of direct zoonotic morbidity worldwide, with $>1$ million cases annually (1). Many species do not exert pathogenic effects; however, there are approximately 30 that can cause morbidity and mortality in humans (2). Most poisonous species fall under the family Buthidae, and in North and South America, eight species of the Centruroides genus cause the majority of illnesses (3). There are a few pathogenic strains in Canada; however, as noted in the present case, imported produce from Central or South America may contain scorpians, producing a risk for local envenomation (4). The first described case in Canada occurred in 1962 (5).

Scorpion venom interferes with neuronal activity through ion channels, resulting in peripheral nervous symptoms, such as paresthesia, pain, altered sensation, spasm and autonomic symptoms (3). Local swelling and systemic gastrointestinal symptoms are also common (1). Rarely, cardiac abnormalities, respiratory failure, pancreatitis, central nervous system abnormalities, hematological abnormalities (6), cytotoxic envenomation (1) and renal failure can ensue (2). It is estimated that $<10 \%$ of all envenomations lead to severe systemic sequelae (1).

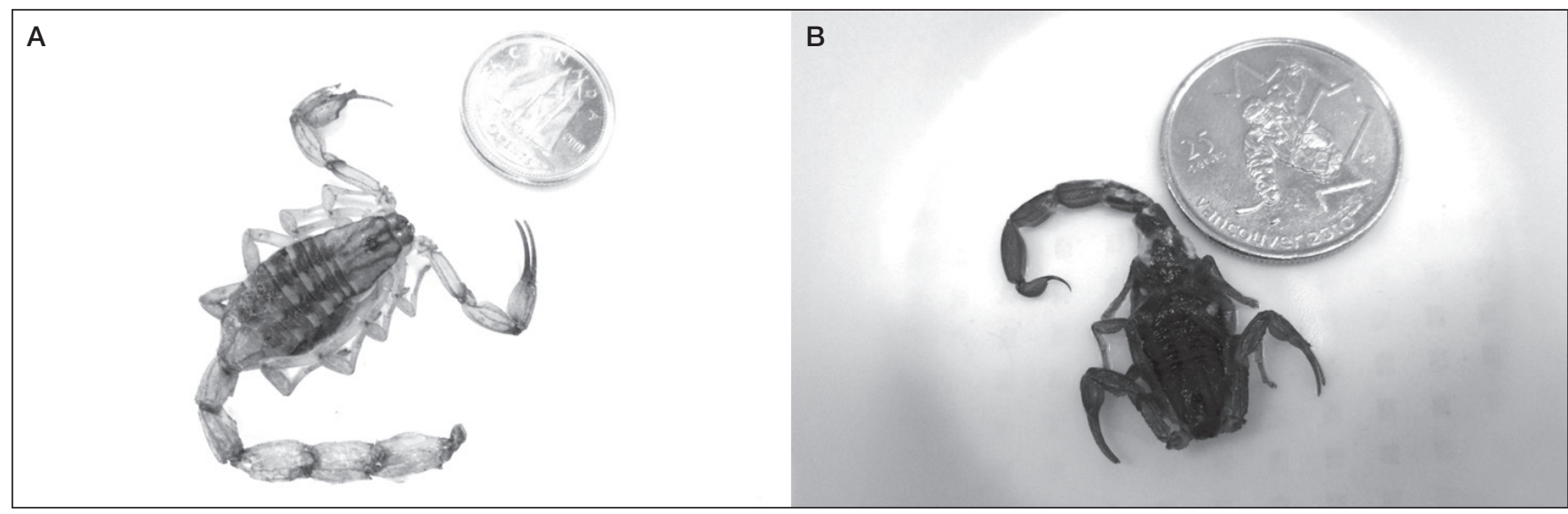

Figure 1) Scorpion imported to Canada in mangoes from South America (A); scorpion imported to Canada in bananas from South America (B)

${ }^{1}$ Division of Infectious Diseases, Department of Medicine, McMaster University, Hamilton; ${ }^{2}$ Tropical Disease Unit, Toronto General Hospital; ${ }^{3}$ Public Health Ontario Laboratories; ${ }^{4}$ Division of Infectious Diseases, Department of Medicine, University of Toronto, Toronto; ${ }^{5}$ Trillium Health Sciences Centre, Mississauga, Ontario

Correspondence: Dr Zain Chagla, Suite 300, 25 Charlton Avenue East, Hamilton, Ontario L8N 1Y2. Telephone 905-517-8012, fax905-523-7352, e-mail zain.chagla@gmail.com 
There is evidence that pulmonary edema and pancreatitis are mediated by the inhibition of angiotensin converting enzyme and the accumulation of bradykinin (7); endogenous acetylcholine and catecholamine release may account for neurological abnormalities (8). Children tend to experience more severe and prolonged symptoms than adults due to the higher ratio of venom injected per $\mathrm{kg}$ of body weight, and are at risk for serious morbidity and mortality (3). Therefore, special attention to counselling for parents regarding all potential bites, including animal and arthropod, is warranted in a pretravel context.

Initial management of scorpion envenomation follows the principles for the management of all intoxications, and involves the assessment of airway, breathing, circulation and resuscitation with intravenous fluids for hypotension, and close monitoring of vital signs. Local wound pain may be treated with infiltration of local anesthetic (3) and other analgesics. Patients with mild local symptoms can be managed symptomatically as an outpatient, with close medical followup, while patients with evidence of autonomic excitation or cardiorespiratory symptoms warrant specialized monitoring in an emergency room or inpatient setting (1).

Given the potential alpha-adrenergic activation, treatment with prazosin for autonomic manifestations has been well described (7). Sedation with benzodiazepines may also be useful for spasms, agitation

\section{REFERENCES}

1. Isbister KG, Bawaskar HS. Scorpion envenomation. N Engl J Med 2014:371:457-63

2. Viswanathan S, Prabhu C. Scorpion sting nephropathy. NDT Plus 2011:4:376-82.

3. Vetter RS, Visscher PK. Bites and stings of medically important venomous arthropods. Int J Dermatol 1998;37:481-96.

4. West PL, Hendrickson, RG. Scorpions on a plane? A case series of non-endemic scorpion envenomations. J Emerg Med 2001;41:89.

5. Wyshynski PE, Little, JA. Scorpionism: The first case reported in Canada. Can Med Assoc J 1962;87:974-5. or anxiety (1). Antivenom (Anascorp, USA) is the only United States Food and Drug Administration-approved antivenom for patients with moderate- to severe-systemic symptoms, and can be obtained through local poison control in the Canadian setting. A randomized clinical trial in 2009 noted that children with significant symptoms treated with antivenom (composed of fragment antigen binding component of antivenom antibody) experienced a more rapid resolution of symptoms, reduced the circulation of venom and the need for sedation (9). Other therapies, depending on clinical condition, include nitroglycerin, dobutamine, atropine and calcium-channel blockers (1).

\section{SUMMARY}

We present a case of scorpion envenomation related to imported produce from South America. Although rare in the Canadian context, front-line clinicians should consider this diagnosis in individuals presenting with an unknown bite, particularly when there is a history of contact with imported goods from endemic regions. Level of care should be commensurate with symptoms and signs, and antivenom therapy should be considered in cases with moderate- to severe-systemic manifestations.

DISCLOSURES: The authors have no financial relationships or conflicts of interest to declare.

6. Warrell DA, Fenner, PJ. Venomous bites and stings. Br Med Bull 1993;49:423-39.

7. Bawaskar H, Bawaskar P. Management of scorpion sting. Heart 1999;82:253-4.

8. Warrell DA. Venomous bites, stings, and poisoning. Infect Dis Clin North Am 2012;26:207-23.

9. Boyer LV, Theodorou AA, Berg RA, Mallie J; Arizona

Envenomation Investigators, Chávez-Méndez A, García-Ubbelohde W, Hardiman S, Alagón A. Antivenom for critically ill children with neurotoxicity from scorpion stings. N Eng J Med 2009;360:2090-8. 


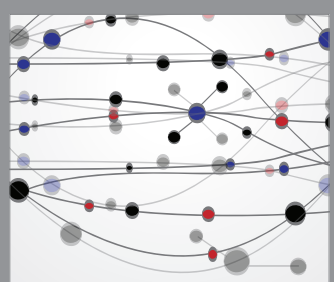

The Scientific World Journal
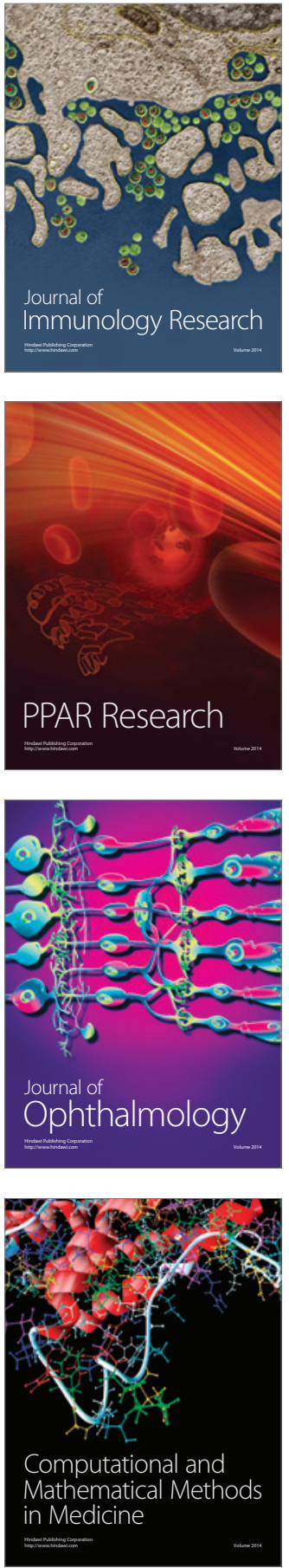

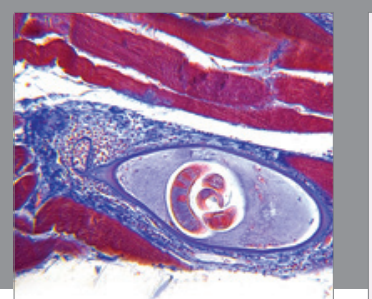

Gastroenterology Research and Practice

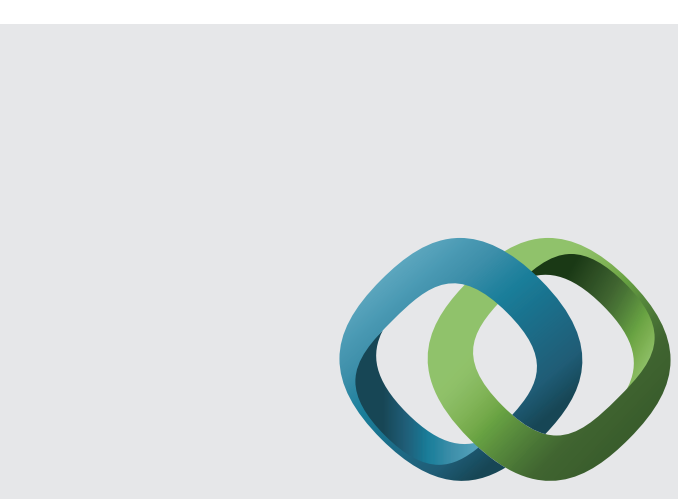

\section{Hindawi}

Submit your manuscripts at

http://www.hindawi.com
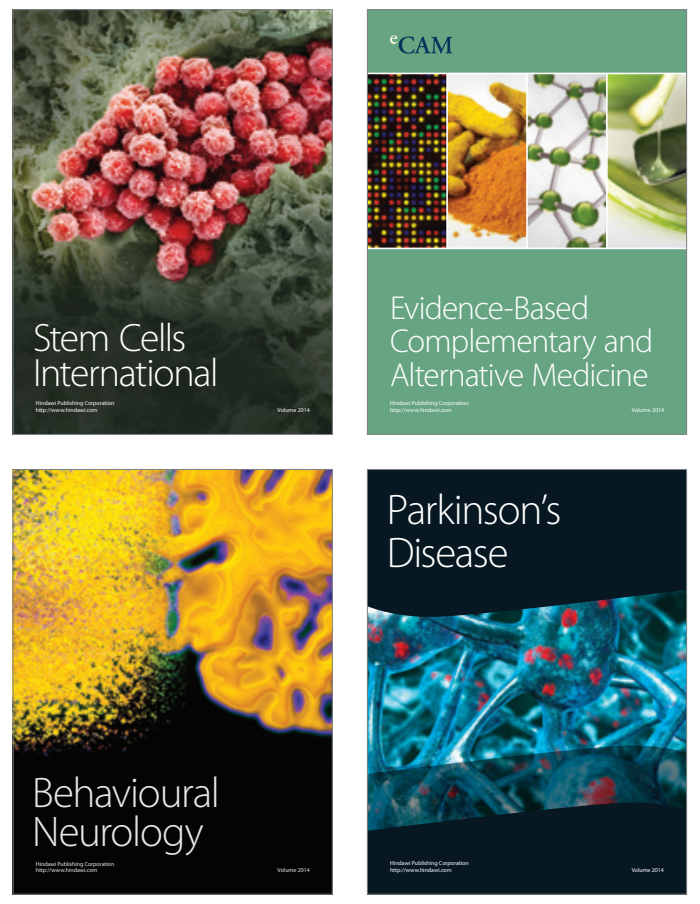
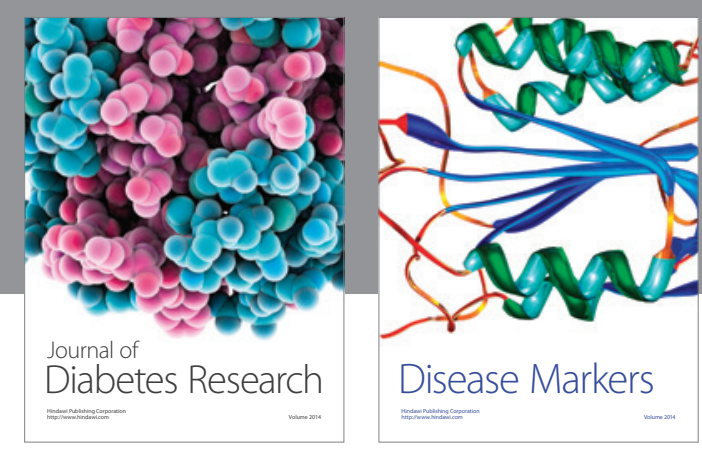

Disease Markers
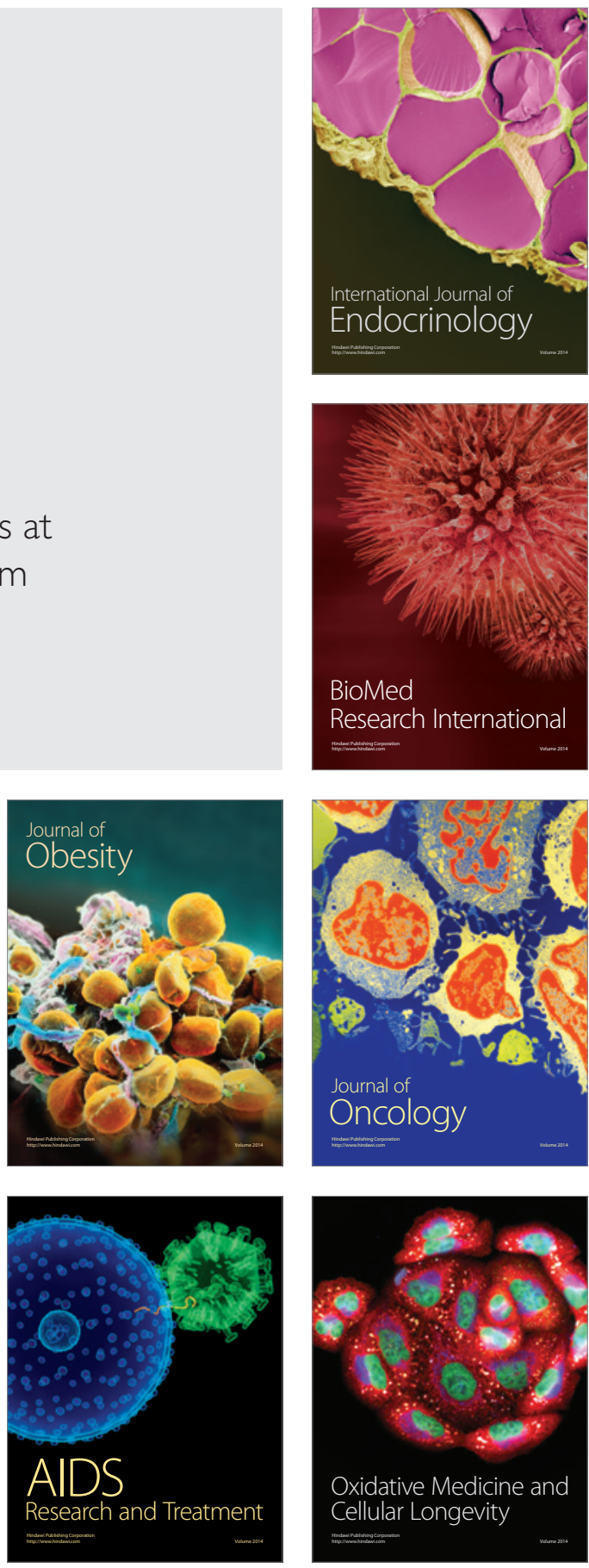